\section{Dimensional Accuracy of Stone Casts Made from Silicone- Based Impression Materials and Three Impression Techniques}

\author{
Rafael Pino Vitti ${ }^{1}$, Marcos Aurélio Bomfim da Silva ${ }^{2}$, Rafael Leonardo Xediek \\ Consani ${ }^{1}$, Mário Alexandre Coelho Sinhoreti ${ }^{1}$
}

\author{
'Department of Restorative \\ Dentistry, Piracicaba School of \\ Dentistry, University of Campinas, \\ Piracicaba, SP, Brazil \\ ${ }^{2}$ Department of Restorative Dentistry \\ and Dental Materials, School of \\ Dentistry, Federal University of \\ Alagoas, Maceió, AL, Brazil
}

Correspondence: Prof. Dr. Mário Alexandre Coelho Sinhoreti, Avenida Limeira, 901, 13414-903 Piracicaba, SP, Brasil. Tel.:+55-19-2106-5374. e-mail: sinhoreti@fop.unicamp.br

\begin{abstract}
The aim of this study was to measure and compare the dimensional accuracy of stone casts of a partially edentulous mandibular arch made by two condensation silicones, two addition silicones and three impression techniques (1-step putty/light-body, 2-step putty/ light-body and monophase technique). A partially edentulous standard stainless steel mandibular arch cast was obtained with reference points on the permanent mandibular right and left canines, and permanent mandibular right and left second molars. The anteroposterior distances (between the mandibular left canine and second molar and between the mandibular right canine and second molar) and transverse distances (between the mandibular left and right canines and between the mandibular left and right second molars) of stainless steel cast were measured by a microscope at $30 \times$ magnification and $0.5 \mu \mathrm{m}$ accuracy. All impressions were made with condensation or addition silicones. The 1- and 2-step putty/light-body impressions were accomplished with putty and light-body materials and the monophase impressions with light-body material only. After the impression procedures, accuracy of each material and technique was assessed measuring the stone casts poured $(n=5)$ from the impressions, by the same microscope. The differences between the values of stone cast and stainless steel cast were calculated, presented as percentages and analyzed statistically by two-way ANOVA and the means compared by Tukey's test $(\alpha=0.05)$. All distances measured on stone casts showed altered dimensions with significantly negative linear changes (shrinkage) as compared to those of the stainless steel cast. The stone casts made from the addition silicones were dimensionally more accurate. No differences were found among the impression techniques.
\end{abstract}

Key Words: silicone elastomers, dental impression technique, dental impression materials, dimensional accuracy.

\section{Introduction}

Several critical procedures must be followed to obtain the mold and to make accurate dental stone casts (1-3). Among them is the correct choice and use of impression techniques (2,3-6) as well as impression materials (4). Over the years, a lot of materials and impression techniques were developed to achieve perfect detail reproduction of the oral environment. The first high accuracy impression material, elastomeric impression material, was used for dental purposes in the 1950s $(1,7)$. Silicone-based impression materials are elastomeric impression materials used in dental practice. The polymerization of these materials occurs by condensation (polydimethylsiloxanes - PDMS) or by addition (polyvinyl siloxanes - PVS) reactions $(2,4,7)$.

The silicones for oral impressions are widely used in dentistry because they have high accuracy and dimensional stability (7-10). Furthermore, these materials have excellent elastic recovery, minimum permanent distortion and good tear strength $(7,8)$. The silicone-based materials are commercially available in different viscosities (11), allowing them to be used in several impression techniques adequate to improve the molds accuracy, such as 1-step putty/light-body technique, 2-step putty/light-body technique and the monophase technique $(6,12-14)$.

Regarding the dimensional accuracy, a recent study showed that almost $90 \%$ of molds presented one or more observable errors, requiring a more critical mold analysis by dental practitioners (15). There are several factors that may affect the dimensional accuracy of elastomeric impression material molds, including the type of the used material viscosity $(4,5,16-18)$, thickness $(16,17)$, the impression technique $(3,4,6,17)$, the adhesion method of impression materials to the tray, time elapsed to cast pouring (17,), the material's hydrophilicity, release of byproducts, polymerization shrinkage, thermal shrinkage and incomplete elastic recovery (15-18).

There are several discussions in the dental literature about the effect of material and impression technique on the cast accuracy and prosthesis fitting. Some authors showed that the cast accuracy is affected more by the used impression technique than by the chosen material $(5,6,18-20)$. Other researchers reported that the impression 
technique does not affect the dimensional accuracy $(3,8,14,21,22)$. Furthermore, some studies showed better dimensional accuracy when an individual acrylic resin tray is used (16). Thus, the aim of this study was to measure and to evaluate the dimensional accuracy of casts made by three impression techniques (1-step putty/light-body, 2-step putty/light-body and monophase) using addition and condensation silicones. The hypotheses were that (1) the addition silicones provide more accurate stone casts than condensation silicones and (2) no differences exist in the dimensional accuracy among the impression techniques.

\section{Material and Methods}

Table 1 displays the materials used in the study. All elastomeric impression materials were used in the putty (type 0) and light-body (type III) viscosities. A partially edentulous stainless steel mandibular arch cast was fabricated with reference points (23) on the permanent

Table 1. Materials used

\begin{tabular}{lc}
\hline Trade names & Manufacturers \\
\hline Zetaplus (PDMS) & Zhemarck, Rovigo, ltaly \\
Oranwash L (PDMS) & Zhemarck, Rovigo, ltaly \\
Xantopren VL Plus (PDMS) & Heraeus Kulzer GmBH, \\
& Hanau, Germany \\
Optosil Comfort (PDMS) & Heraeus Kulzer GmBH, \\
& Hanau, Germany \\
Express Regular Set (PVS) & 3M Dental Products, CA, USA \\
Aquasil Ultra Regular Set (PVS) & Dentsply lnd. e Com. Ltda, \\
& Petrópolis, RJ, Brazil
\end{tabular}

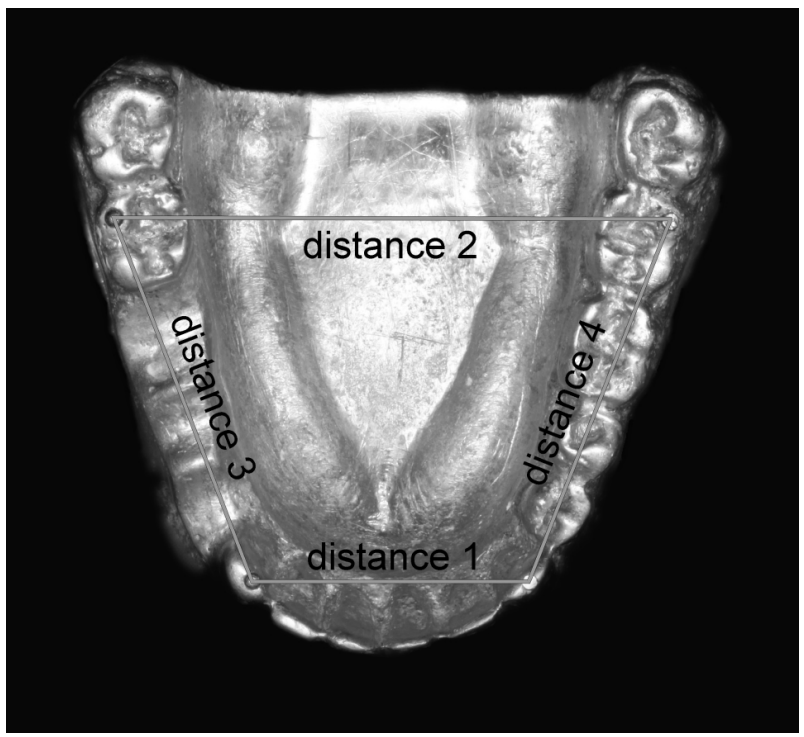

Figure 1. Stainless steel cast and the distances measured in the study. mandibular left and right canines, and permanent mandibular left and right second molars. The transverse distances between the permanent mandibular left and right canines (distance 1) and between the mandibular left and right second molars (distance 2) and the anteroposterior distances between the mandibular right canine and right second molar (distance 3 ) and the mandibular left canine and left second molar (distance 4) were measured using a microscope at 30x magnification (Measuring Microscope STM; Olympus Optical Co., Tokyo, Japan) (Fig. 1). Handling was performed according the manufacturers' instructions and impressions were made under controlled temperature and relative humidity $\left(23 \pm 2{ }^{\circ} \mathrm{C}\right.$ and $\left.50 \pm 10 \%\right)(10)$.

For the 1-step putty/light-body technique, the putty

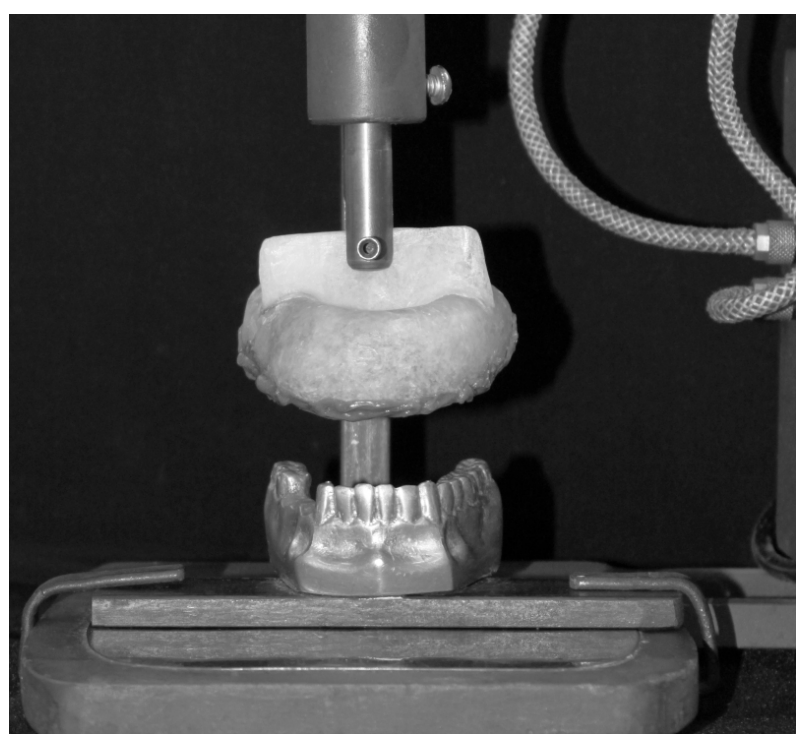

Figure 2. Detachment tray/cast using an individual acrylic resin tray.

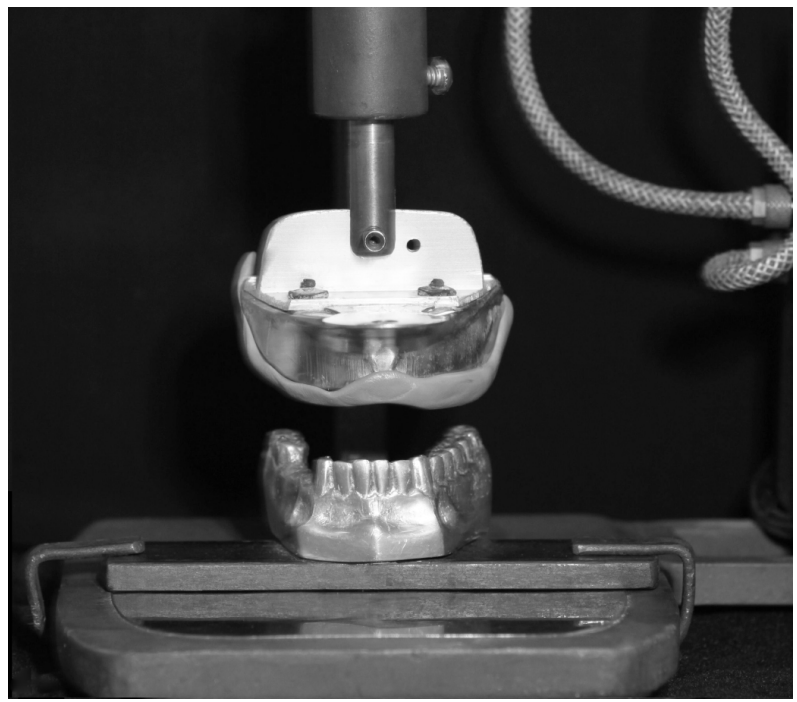

Figure 3. Detachment tray/cast using a metallic stock tray. 
and light-body material were handled together. The impressions were made using metallic stock trays I-3 (Tecnodent, Casalecchio di Reno, Italy). The elastomeric impression material of putty viscosity was handled using plastic gloves to avoid the inhibition of polymerization reaction by contaminants of the latex gloves.

With the 2-step putty/light-body technique was used a polypropylene spacer $2 \mathrm{~mm}$ thick on the stainless steel cast to form a space (relief). Thus, a first impression was made using a metallic stock I-3 tray with putty material. A first mold was produced using this impression. Then, the spacer was removed and the light-body material handled and placed over the putty material, and the tray replaced on the stainless steel cast to accomplish the final impression.

The monophase technique was accomplished in a single-step procedure with light-body viscosity only. Individual acrylic resin trays (Vipi Flash; VIPI, Pirassununga, SP, Brazil) with internal $2 \mathrm{~mm}$ relief (24) were manufactured. A layer of universal adhesive (Heraeus Kulzer GmBH, Hanau, Germany) was applied inside each tray. The drying time for the adhesive was $5 \mathrm{~min}$. After handling, the elastomeric impression material was placed to cover the tray's internal surface, allowing a homogeneous distribution of the material.

For all impression techniques, the group tray/ impression material was positioned and seated on the stainless steel cast from posterior to anterior direction and the tray detachment movement was standardized by a pneumatic equipment in order to avoid distortions in the mold $(22,24)$ (Figs. 2 and 3).

Dental stone type IV (Durone; Dentsply, Petrópolis, RJ, Brazil) was used in a water/powder ratio of $28.5 \mathrm{~mL} / 150 \mathrm{~g}$ for stone cast pouring. The casts were poured after a period of $30 \mathrm{~min}$, to allow the correct elastic recovery of impression materials. Five samples were produced for each material and impression technique. As in the stainless steel cast, for each distance among the teeth, three readings were made by a single calibrated operator and the means were calculated.

The means were recorded and compared with the original means obtained from the stainless steel cast. The differences between the values of stone cast and stainless steel cast were calculated and presented as percentages. If negative, the data indicated that there was decrease of the distances (shrinkage); if positive, it indicated volume increase (expansion). Data were analyzed statistically by two-way analysis of variance and Tukey's test at a $5 \%$ significance level.

\section{Results}

Tables 2-5 present the percentages of dimensional alteration for each distance, according to the impression materials and techniques. All materials showed shrinkage. The condensation silicones had the highest values of dimensional alteration. No significant difference was found ( $p>0.05$ ) among the addition silicones, except for

Table 2. Mean dimensions and standard deviations (\%) of stone casts for distance 1

\begin{tabular}{lccc}
\hline Material/Technique & 2-step & 1-step & Monophase \\
\hline Optosil/Xantopren & $-0.20 \pm 0.02 \mathrm{a}, \mathrm{A}$ & $-0.20 \pm 0.04 \mathrm{a}, \mathrm{A}$ & $-0.20 \pm 0.03 \mathrm{a}, \mathrm{A}$ \\
Zetaplus/Oranwash & $-0.19 \pm 0.01 \mathrm{a}, \mathrm{A}$ & $-0.19 \pm 0.02 \mathrm{a}, \mathrm{A}$ & $-0.19 \pm 0.02 \mathrm{a}, \mathrm{A}$ \\
Aquasil & $-0.04 \pm 0.01 \mathrm{~b}, \mathrm{~A}$ & $-0.05 \pm 0.01 \mathrm{~b}, \mathrm{~A}$ & $-0.05 \pm 0.02 \mathrm{~b}, \mathrm{~A}$ \\
Express & $-0.02 \pm 0.02 \mathrm{~b}, \mathrm{~A}$ & $-0.02 \pm 0.01 \mathrm{~b}, \mathrm{~A}$ & $-0.02 \pm 0.01 \mathrm{~b}, \mathrm{~A}$ \\
\hline
\end{tabular}

Means followed by different lowercase letters in columns and uppercase letters in rows are statistically different at 5\% by Tukey's test.

Table 3. Mean dimensions and SD (\%) of stone casts for distance 2

\begin{tabular}{lccc}
\hline Material/Technique & 2-step & 1-step & Monophase \\
\hline Optosil/Xantopren & $-0.17 \pm 0.01 \mathrm{a}, \mathrm{A}$ & $-0.17 \pm 0.01 \mathrm{a}, \mathrm{A}$ & $-0.17 \pm 0.01 \mathrm{a}, \mathrm{A}$ \\
Zetaplus/Oranwash & $-0.15 \pm 0.01 \mathrm{a}, \mathrm{A}$ & $-0.16 \pm 0.02 \mathrm{a}, \mathrm{A}$ & $-0.15 \pm 0.01 \mathrm{a}, \mathrm{A}$ \\
Aquasil & $-0.03 \pm 0.01 \mathrm{~b}, \mathrm{~A}$ & $-0.03 \pm 0.01 \mathrm{~b}, \mathrm{~A}$ & $-0.03 \pm 0.01 \mathrm{~b}, \mathrm{~A}$ \\
Express & $-0.01 \pm 0.01 \mathrm{c}, \mathrm{A}$ & $-0.01 \pm 0.01 \mathrm{c}, \mathrm{A}$ & $-0.01 \pm 0.01 \mathrm{c}, \mathrm{A}$ \\
\hline
\end{tabular}

Means followed by different lowercase letters in columns and uppercase letters in rows are statistically different at $5 \%$ by Tukey's test.

Table 4. Mean dimensions and SD (\%) of stone casts for distance 3

\begin{tabular}{lccc}
\hline Material/Technique & 2-step & 1-step & Monophase \\
\hline Zetaplus/Oranwash & $-0.40 \pm 0.02 \mathrm{a}, \mathrm{A}$ & $-0.42 \pm 0.01 \mathrm{a}, \mathrm{A}$ & $-0.40 \pm 0.02 \mathrm{a}, \mathrm{A}$ \\
Optosil/Xantopren & $-0.39 \pm 0.02 \mathrm{a}, \mathrm{A}$ & $-0.40 \pm 0.02 \mathrm{a}, \mathrm{A}$ & $-0.39 \pm 0.03 \mathrm{a}, \mathrm{A}$ \\
Aquasil & $-0.21 \pm 0.01 \mathrm{~b}, \mathrm{~A}$ & $-0.23 \pm 0.02 \mathrm{~b}, \mathrm{~A}$ & $-0.22 \pm 0.02 \mathrm{~b}, \mathrm{~A}$ \\
Express & $-0.18 \pm 0.02 \mathrm{~b}, \mathrm{~A}$ & $-0.18 \pm 0.03 \mathrm{~b}, \mathrm{~A}$ & $-0.18 \pm 0.01 \mathrm{~b}, \mathrm{~A}$ \\
\hline
\end{tabular}

Means followed by different lowercase letters in columns and uppercase letters in rows are statistically different at $5 \%$ by Tukey's test.

Table 5. Mean dimensions and SD (\%) of stone casts for distance 4.

\begin{tabular}{lccc}
\hline Material/Technique & 2-step & 1-step & Monophase \\
\hline Zetaplus/Oranwash & $-0.37 \pm 0.02 \mathrm{a}, \mathrm{A}$ & $-0.40 \pm 0.04 \mathrm{a}, \mathrm{A}$ & $-0.37 \pm 0.01 \mathrm{a}, \mathrm{A}$ \\
Optosil/Xantopren & $-0.37 \pm 0.01 \mathrm{a}, \mathrm{A}$ & $-0.38 \pm 0.02 \mathrm{a}, \mathrm{A}$ & $-0.37 \pm 0.02 \mathrm{a}, \mathrm{A}$ \\
Aquasil & $-0.16 \pm 0.03 \mathrm{~b}, \mathrm{~A}$ & $-0.16 \pm 0.01 \mathrm{~b}, \mathrm{~A}$ & $-0.16 \pm 0.02 \mathrm{~b}, \mathrm{~A}$ \\
Express & $-0.13 \pm 0.02 \mathrm{~b}, \mathrm{~A}$ & $-0.13 \pm 0.01 \mathrm{~b}, \mathrm{~A}$ & $-0.13 \pm 0.01 \mathrm{~b}, \mathrm{~A}$ \\
\hline
\end{tabular}

Means followed by different lowercase letters in columns and uppercase letters in rows are statistically different at $5 \%$ by Tukey's test. 
the distance 2 where Express showed more dimensional accuracy than Aquasil in all impression techniques. No significant difference was found ( $p>0.05)$ among the impression techniques.

\section{Discussion}

The impression procedure must reproduce accurately the oral structure details to allow the manufacturing of accurate stone casts (1). Dentures for patient oral rehabilitation will be fabricated on these casts. The fit accuracy of a denture is a key factor to long-term prosthetic treatment success and therefore to avoid misfit, all clinical and laboratory procedures must be followed $(1,2)$.

In all studied impression techniques, the addition silicones produced more accurate stone casts than the condensation silicones. Therefore, the first hypothesis was accepted. The worse results of condensation silicones can be explained by the significantly continuous polymerization and the evaporation of volatile byproducts, such as ethanol, that can damage the material's dimensional stability and accuracy (7). The addition silicones have excellent mechanical and physical properties and do not form byproducts during or after the polymerization reaction (7). All these factors contribute for avoiding the impression material distortion, allowing it to remain dimensionally stable and provide accurate stone casts (1).

The most common dimensional changes that occur with the silicone-based impression materials are related to the material's polymerization shrinkage and to temperature differences between the oral environment and the room where the mold will be stored (thermal shrinkage). The incomplete elastic recovery is another important factor. Some authors $(4,10,25)$ reported that high-viscosity elastomeric impression materials might present little shrinkage and consequently small values of dimensional change due to the high amount of filler. A low matrix/ filler ratio leads to the formation of a material with low polymerization shrinkage (25). However, a high amount of filler makes the material less elastic and fluid, resulting in a reduced accuracy $(4,25)$. The variation of the composition of each material may cause differences in the mechanical and chemical properties among materials of the same type, which explains the small difference found in this study for the addition silicones (Aquasil and Express).

No difference was found among the three impression techniques in this study, neither in other researches that showed that the dimensional accuracy alteration is not dependent on the used impression technique $(3,8,14,21,22)$. Thus, the second hypothesis was also accepted. Furthermore, despite the statistically significant differences found in the elastomeric impression materials, all impression materials and techniques produced accurate casts as recommended by the $4823: 2000$ ISO standard (11). In this in vitro study the detachment movement between stainless steel cast and tray was standardized to minimize the effects of tilting movement on the mold accuracy. Clinically, the tray removal movement from oral cavity is a critical process that may compromise the mold accuracy.

Several clinical and laboratory steps should be considered for the correct choice of impression technique. The monophase technique seems to be the easiest because it uses only one material with a single viscosity. However, the need to make the first impression in order to manufacture the individual tray with internal relief increases the required clinical sessions (24). It is not indicated that these trays be used on the same day of its fabrication because most acrylic resin shrinkage occurs during the first $10 \mathrm{~h}$. The application of an adhesive tray is needed also to provide better adhesion of the material to tray (24) and minimize the tensions between the tray and impression material during the detachment movement between tray and oral cavity (9). In the 2-step putty/light-body technique care should be taken for the correct replacement of mold in the patient's mouth and the need of a relief that may cause stress in the impression material. Any mistake in these steps can cause distortions that will result in dimensional accuracy alterations (18). The 1-step putty/light-body technique reduces chair time to allow one impression with two materials, but a simultaneous shrinkage of materials with different viscosities and characteristics occurs. Furthermore, the reproduction of details may be performed by the putty material and not by the light-body material. This situation as well as the presence of bubbles in the impression material (6) can occur by excessive pressure applied during the impression and consequent flow of the light-body material (18). The need of a second person to aid the material handling is another factor to be considered.

It seems that the factors that affect the reproduction and accuracy of molded structures are associated more with the impression materials than the impression technique (3). Different protocols, such as the application or not of adhesives in trays (18), may explain the differences found among the studies regarding the impression techniques. The choice of a product for a particular clinical application should be based on the material's properties rather than on the type and class of impression material. Dental professionals should be informed about the advantages and disadvantages of each material and impression techniques to adequately use them in clinical practice and provide proper clinical longevity to the prosthetic treatment. Based on the results of this study, it is recommended that dentists use the technique that they are most familiar with, respecting the limitations of each technique, as laboratory studies control several factors that may cause mold distortion. 


\section{Resumo}

0 objetivo deste estudo foi mensurar e comparar a precisão dimensional de modelos de gesso de um arco mandibular parcialmente edêntulo feitos a partir de dois silicones por condensação, dois silicones por adição e três técnicas de moldagem (dupla mistura, reembasamento e moldeira individual). Um modelo metálico padrão de um arco mandibular parcialmente edêntulo foi obtido com pontos de referência nos caninos mandibulares permanentes esquerdo e direito, e segundo molares mandibulares permanentes esquerdo e direito. As distâncias anteroposteriores (entre o canino e segundo molar mandibulares esquerdos e entre o canino e segundo molar mandibulares direitos) e as distâncias transversais (entre os caninos mandibulares esquerdo e direito e entre os segundos molares mandibulares esquerdo e direito) do modelo metálico foram mensuradas através de um microscópio com $30 \mathrm{x}$ de aumento e $0,5 \mu \mathrm{m}$ de precisão. Todas moldagens foram feitas com silicones por condensação e adição. As técnicas de dupla mistura e reembasamento foram realizadas com materiais nas viscosidades massa e leve e a técnica da moldeira individual somente com material leve. Após os procedimentos de moldagem, a precisão de cada material e técnica foi aferida medindo os modelos de gesso vazados $(n=5)$ dos moldes, sob o mesmo microscópio. As diferenças entre os valores dos modelos de gesso e do modelo metálico foram calculadas, apresentadas como porcentagens e analisadas estatisticamente através da análise de variância e teste de Tukey $(\alpha=0,05)$. Todas as distâncias mensuradas nos modelos de gesso apresentaram dimensões alteradas com alterações lineares negativas (contração) significativas quando comparadas as medidas do modelo metálico. Os modelos de gesso feitos a partir de silicones por adição foram dimensionalmente mais precisos. Não foram encontradas diferenças entre as técnicas de moldagem.

\section{Acknowledgements}

The authors acknowledge CAPES (Coordenação de Aperfeiçoamento de Pessoal de Nivel Superior - Brazil) for the financial support.

\section{References}

1. Maruo Y, Nishigawa G, Oka M, Minagi S, Irie M, Suzuki K. Tensile bond strength between custom tray and elastomeric impression material. Dent Mater J 2007;26:323-328.

2. Shah $S$, Sundaram G, Bartlett $D$, Sherriff M. The use of a 3D laser scanner using superimpositional software to assess the accuracy of impression techniques. J Dent 2004;32:653-658.

3. Hung SH, Purk JH, Tira DE, Eick JD. Accuracy of one-step versus twostep putty-wash addition silicone impression technique. J Prosthet Dent 1992;67:583-589.

4. Chen SY, Liang WM, Chen FN. Factors affecting the accuracy of elastomeric impression materials. J Dent 2004;32:603-609.

5. Levartovsky S, Zalis M, Pilo R, Harel N, Ganor Y, Brosh T. The effect of one-step vs. two-step impression techniques on long-term accuracy and dimensional stability when the finish line is within the gingival sulcular area. J Prosthodont 2013. [Epub ahead of print. DOI: 10.1111/ jopr.12062.].

6. Nissan J. Accuracy of three polyvinyl siloxane putty-wash impression techniques. J Prosthet Dent 2000;83:161-165.
7. Christensen GJ. What category of impression material is best for your practice? J Am Dent Assoc 1997;128:1026-1028.

8. Brosky ME. Laser digitalization of casts to determine the effect of tray selection and cast formation technique on accuracy. J Prosthet Dent 2002;87:204-209.

9. Bindra B, Heath JR. Adhesion of elastomeric impression materials to trays. J Oral Rehabil 1997;24:63-69.

10. Mandikos MN. Polyvinyl siloxane impression materials: an update on clinical use. Aust Dent J 1998;43:428-434.

11. International Organization for Standardization. ISO-4826. Elastomeric impression materials. Geneva: ISO; 2000.

12. Saunders WP, Sharkey SW, Smith GM, Taylor WG. Effect of impression tray design and impression technique upon the accuracy of stone casts produced from a putty-wash polyvinyl siloxane impression material. $J$ Dent 1991;19:283-289.

13. Pameijer $\mathrm{CH}$. A one-step putty-wash impression technique utilizing vinyl polysiloxanes. Quintessence Int Dent Dig 1983;14:861-863.

14. Johnson GH, Craig RG. Accuracy of addition silicones as a function of technique. J Prosthet Dent 1986;55:197-203.

15. Samet N, Shohat M, Livny A, Weiss El. A clinical evaluation of fixed partial denture impressions. J Prosthet Dent 2005;94:112-117.

16. Eames WB, Sieweke JC, Wallace SW, Rogers LB. Elastomeric impression materials effect of bulk on accuracy. J Prosthet Dent 1979;41:304-307.

17. Nassar U, Oko A, Adeeb $\mathrm{S}$, El-Rich M, Flores-Mir C. An in vitro study on the dimensional stability of a vinyl polyether silicone impression material over a prolonged storage period. J Prosthet Dent 2013;109:172-178.

18. Caputi $S$, Varvara G. Dimensional accuracy of resultant casts made by a monophase, one-step and two-step, and a novel two-step putty/ light-body impression technique: an in vitro study. J Prosth Dent 2008;99:274-281.

19. Singh K, Sahoo S, Prasad KD, Goel M, Singh A. Effect of different impression techniques on the dimensional accuracy of impressions using various elastomeric impression materials: an in vitro study. J Contemp Dent Pract 2012;13:98-106.

20. Shafa S, Zaree Z, Mosharraf R. The effects of custom tray material on the accuracy of master casts. J Contemp Dent Pract 2008;9:49-56.

21. Idris $B$, Houston $F$, Claffey N. Comparison of the dimensional accuracy of one- and two-step techniques with the use of putty/wash addition silicone impression materials. J Prosthet Dent 1995;74:535-541.

22. Lee IK, DeLong R, Pintado MR, Malik R. Evaluation of factors affecting the accuracy of impressions using quantitative surface analysis. Oper Dent 1995;20:246-252.

23. Consani RLX, Domitti SS, Mesquita MF, Consani S. Influence of flask closure and flask cooling methods on tooth movement in maxillary dentures. J Prosthodont 2006;15:229-234.

24. Kumar V, Aeran H. Evaluation of effect of tray space on the accuracy of condensation silicone, addition silicone and polyether impression materials: an in vitro study. J Indian Prosthodont Soc 2012;12:154-160.

25. Carlo HL, Fonseca RB, Soares CJ, Correr AB, Correr-Sobrinho L, Sinhoreti MA. Inorganic particle analysis of dental impression elastomers. Braz Dent J 2010;21:520-527. 